\title{
Research on Practical Teaching Mode of Military Service Education Based on Operational Flow
}

\author{
Lin Zhang \\ Department of missile, Dalian Naval Academy, Dalian, 116018,China \\ mailbox1015@126.com
}

Keyword: Operational process; Practical teaching; Mode

\begin{abstract}
Aiming at the problems existing in the teaching of military service education at present, the practical teaching mode is studied with the core of operational process and all factors. According to the characteristics of the curriculum and teaching objectives, the basic principles, specific methods and the key issues that should be grasped are put forward under the guidance of the pro-experience teaching theory. Based on the problem-based seminars, war-based heuristic, tactical operating system based on the scheduled work, based on the combat simulation system, integrated exercises and naval units based on actual combat exercises and other practical teaching model draws on the unit's post war operational processes, The change from proxy teaching to pro-experience teaching can realize the logic of practice instead of the logic of knowledge, and put the requirements of actual combat training into practice in all aspects of combat personnel training to ensure that teaching can further focus on actual combat and move closer to the troops to promote the teaching process and combat docking process.
\end{abstract}

Due to its practical requirements such as military proximity, comprehensiveness of factors and creativity of thinking, the military basic course requires learners to learn through personal and direct experience. Therefore, military teaching should adopt a teaching mode based on the operational process. The core of this mode is the unification of learning and operational processes. That is, the teaching process refers to the combat process of serving positions in the military and integrates related theoretical knowledge and professional skills , Command ability, style development and requirements, from proxy teaching to pro-experience teaching, practical logic to replace the logic of logic, and promote the combat process and the docking process of teaching.

\section{The Basis of Military Teaching Mode Selection Basis}

The Characteristics of Military Basic Courses. The purpose of studying the characteristics of military teaching lies in analyzing and recognizing the particularity of the contradiction in military teaching and laying the foundation for the study of military teaching theory and practice.

Closeness

The purpose of military teaching is to improve the students' tactical thinking and the ability to organize and direct combat. Such improvement in level and ability can be achieved only through training under conditions of actual combat. By adopting this content and selecting and applying the organizational form of military teaching, Methods and means to maximize to create a teaching environment close to combat, to enable students to produce similar psychological activities, feel and overcome various psychological difficulties, so as to withstand the actual combat training.

\section{comprehensive}

Combining military ideology, military command, military geography, military logistics, military meteorology, military technology, military (military) and foreign military knowledge into a single furnace, it is necessary to solve the problems encountered in combat command and thinking, But also to solve the problems of skills and skills in combat command; it is necessary to develop both intellectual and non-intellectual factors.

Continuity

The implementation process of military teaching is a process that is carried out on a stage-by-stage basis and from sub-level to advanced level. The various stages of combat and the 
fighting are all subject to strict control over time and space for combat. They usually concentrate on time or even in strict accordance with the operational time, One-time completed. Students learn tactical thinking activities, before and after the battle phase of the situation connected to the need for students to conduct a coherent analysis of comprehensive, reasoning to judge.

Creative

Under the conditions of informationization, the operations are changing the concept of the traditional space, time and speed of warfare, and changing the traditional combination methods between the military and armed services so as to make great changes in the form and mode of operation of the war. This inevitably makes the operational uncertainty More prominent. The uncertainty of future fighting determines that the knowledge taught in military teaching is relativistic and needs constant improvement and development in practice. Fundamentally speaking, military teaching is an innovative work in which learning is known, exploration is unknown, discovering more elements and exploring factors.

To sum up, the military teaching must, at a time and in a space, study the various stages of combat and the fighting in a close combat environment. Students should analyze and analyze synthetically and inference reasonably the circumstances of the relevant season and make corresponding Conclusions and proper handling of the process of training students to combat thinking and thinking. Therefore, the contents of military education must take the combat operation as the main line, and the teaching should be implemented in a one-time and consistent manner in strict accordance with the operational time.

Pro-experience Teaching Theory. "Pro-empirical" teaching theory stems from Dewey's theory of empirical learning. Kolb thinks that adult learning is an experience-based process. The process includes direct experience observation, reflective observation, abstract understanding and application practice to form a The process of recycling. In a nutshell, it is a teaching method that aims to cultivate students 'ability of autonomous learning and innovation by acquiring and experiencing students' own experience and practice. It emphasizes the openness of classes and the active participation of students. The role of this teaching method in military teaching

To cultivate the ability of trainees to comprehensively and flexibly use knowledge and avoid the separation of knowledge and ability

Knowledge is dead when it is learned, alive when it is used, and the fact that knowledge is not equal to ability is well known. However, in fact, the phenomenon of separation of knowledge and ability is not uncommon. On the one hand, proactive learning can test the validity of the knowledge learned by SRL and on the other hand, it provides opportunities for the application of knowledge or the conversion of knowledge into abilities.

To improve students' situational (emergency situation) grasp and ability to handle

Perception and coping level of the current combat situation (emergency situation) is an important part of individual emotional intelligence. When performing empirical learning such as role play and case analysis, the learner will mobilize the physical participation of the autonomic nervous system , Will be stored for a long time in the learner's heart, and will contact with other experiences to enable individuals to conduct a profound reflection, and then change some of the learners' cognitive and behavioral modes, play a role in gradually improving the ability to grasp and handle the situation.

To improve students' self-awareness and comprehensive awareness

In the process of dealing with others, we have to share and collide ourselves with other people's thoughts and ideas. There will be interaction between emotional emotions and behaviors of others and others in role-playing, all of which are traditional agents Sexual learning does not have. In this kind of experience-based learning, learners can better perceive themselves and others, not only realizing their advantages and strengths more fully and others, but also more carefully and specifically realizing the shortcomings and deficiencies of themselves and others.

To improve cooperation and enhance team awareness

Under the condition of informationization, maritime operations must obtain the support of space information and must be supported by other services. If they are supported by the Air Force, 
missiles, electronic warfare and space forces, they must obtain the support of the network-centric communications data link. Any one combat node must require the support and coordination of multiple nodes, and can form the system combat capability, which is very important to the synergy effect with each combat node. In classroom learning, the corresponding knowledge is already known in classroom teaching. However, as a positive person, the psychological functions of students in the design situation such as consciousness, attention, memory, emotion and behavior are at a higher level of activation and coordination.

In summary, the pro-experience teaching method is to let students through their own personal, direct experience to learn, what they learned is their first-hand experience and skills directly. Students from passive acceptance into an active participation, the instructor from the whole classroom spoon-fed into a guide to guide students to think and summarize. These are compatible with the essence of military service educationand teaching rules. The vast majority of military service education belong to conceptual forms. They are based on the teaching of improving the students' mental skills. They require individual internalization of students. The teaching process does not exist. Choosing the appropriate teaching mode can promote the improvement of combat command ability. Practical teaching mode is the most effective way to carry out the pro-experience teaching method.

\section{The Practice of Teaching the Implementation of the Basic Principles}

to improve the operational command and tactical thinking as the goal

Tactical thinking is the basis of combat command capability, combat command capability, tactical thinking is bound to high levels. However, the high level of tactical thinking, not the ability of combat command must be strong. The strong ability of organizing and directing combat is a solid basis for military theory. The combination of superb tactical thinking, superb command art, and good psychological quality of combat is the core of commanders' military qualities and the level of tactical thinking. The strength of combat command capability is not only a measure of a commander of the main indicators of eligibility, but also to test the level of military teaching objective quality standards.

under the conditions of information actual combat needs at sea

Starting from the actual needs of teaching, starting from the actual conditions of the partial warfare at sea under the conditions of informationization, the military teaching should be brought close to actual combat to the maximum extent. The objective laws reflecting military teaching embodying the actual needs of military practice embody the fundamental characteristics that military teaching must conform to the needs of maritime wars. It is the basic guiding ideology of military teaching and an objective measure of testing military teaching quality.

to students independent exploration as the core

Military teaching has an extremely rich content, contains extremely profound ideological and scientific. For such a complete knowledge system to learn and master, and ultimately through the students' self-understanding, self-digestion, self-absorption can be completed. Without arduous and profound independent thinking, it is impossible to grasp the basic knowledge, but also can not achieve the transformation from knowledge to ability. Students' learning and mastery of existing knowledge can not fully meet the needs of maritime operations under informational conditions. For such an unknown area, students only gradually approached it and recognized it by thinking independently in their teaching practice.

to practice teaching as the main link

Military service educationare highly applied knowledge, learning to learn, to explore unknown teaching activities. The purpose is not only to master the basic knowledge and skills of combat, but also in practice can be flexibly applied. Therefore, the practical teaching should be strengthened in military teaching so as to create the conditions for students to apply their knowledge and flexibly solve practical problems. The strengthening of practical teaching links in military service educationis mainly solved through application of teaching. The main forms of group operations, marshalling operations, staging operations and coherent operations, a comprehensive exercise. The 
main methods are case teaching, case teaching, program planning, want to set homework, simulation and so on. Through systematic and step-by-step application of instructional instruction, multi-level and multi-subject teaching, multi-form and multi-situation practical teaching have been formed to enable students to exercise their full potential. When conditions permit, trainees should also be organized to use naval surface ships to carry out actual exercises at sea. They can also use the surrounding troops to visit and see and learn to create conditions for improving their abilities.

\section{The Typical Method of Teaching}

based on the issue of seminar teaching mode

Knowledge originated in the problem, the problem is knowledge. To conduct seminar-based teaching on the basis of questions is to summarize the knowledge system summarized as different "problems", and take the reality of the focus, hot issues and problems as the main line to study the past "problems" and the future of the future May be facing the "problem" to explore as a supplement, with the "problem" to job knowledge of "string" together to enhance the ability of students to analyze and solve problems.

heuristic teaching model based on war

The heuristic teaching model based on the war example refers to the teaching activities of the students studying and studying the examples of combat under the guidance of the instructors. In the case teaching, instructors use various teaching methods to present vividly the historical facts of some battles in front of the trainees. The trainees can learn from the positive and negative aspects of the experience and lessons in the battle of organizing and implementing to enrich the perceptual knowledge and deepen the understanding of Tactical and scientific understanding of the use of tactical knowledge and skills to master the way to find out the rules of combat guidance to explore and solve the future high-tech combat new issues and improve the level of tactical thinking and organizational and command ability. And can take typical cases as the carrier of classroom teaching, and actively explore the hidden problems in the battle difficult problems and factors that make gains and losses to discuss, so as to cultivate the creative thinking and creative thinking and problem solving and improve the ability of learners to solve practical problems A teaching form. Essentials of Heuristic Teaching Based on Battle Cases.

based on the information system to decide the job

Want to assign homework teaching in military academies and schools all over the world have been widely used. The US Army's Synthetic Military Staff College requires all officers to complete six missed assignments during the nine weeks of school and virtually cancel the class lectures. All relevant theoretical knowledge (15 basic courses) is arranged in the preparatory learning phase prior to admission carry out. Based on the information system to decide the job, make full use of and rely on the command and training information system and other simulation training platform, operating conditions closer to the actual combat, the participants in a real combat environment for a variety of battle tactics to be homework to achieve the desired teaching information, The purpose is to guide students to translate book knowledge into military skills, improve their information literacy, command and decision-making skills and strategic level.

a comprehensive exercise based on combat simulation system

The combat simulation system is used to establish the approximate combat battlefield environment, with the command post driving the naval and naval vessels of both the Red and Blue as the main mode. The students at each level respectively assume the roles of formation and single-ship commanders, and take the roles of back-to-back confrontation, multitasking and multimarshalling and continuous implementation. It mainly examines students' understanding and comprehensive utilization of various professional knowledge and tactical command theories, and strengthens the command and decision-making, tactical utilization and training of tactics and training methods to promote their thinking and combat command capabilities. .

naval exercises based on naval forces

Based on the comprehensive exercise, students are familiar with the operational background, the use of force, and the methods of combat. The reference model of the ship's deputy is the full 
training assessment, and the naval forces use simulated red and blue forces to carry out maritime military exercises.

\section{The Implementation of Teaching Should Grasp the Key Issues}

The basic guiding ideology of military teaching is that both military and religious coherence. Strive to narrow the gap between teaching and actual combat, to meet the actual needs as an examination of each subject, every training problem of objective quality of teaching standards.

highlight the research on the fighter

Only by studying enemy troops and mastering the development and changes of combatant targets can military teaching improve teaching pertinence. Studying the enemy forces should focus on the task of attacking and defending tactics of the enemy forces, the characteristics of combat operations, the basic tactics and the law of operation as well as the application of high-tech weaponry and equipment in offensive and defensive operations in accordance with the teaching tasks. By analyzing the strength and weakness of the enemy forces, we will study and explore new tactics to combat the inferior enemy of high-tech equipment by using inferior equipment.

highlight the research methods of warfare

The military teaching should proceed from the objective reality and base its efforts on the existing equipment of our armed forces with a view to possible development. On the basis of inheriting and developing our traditional military tactics, we should study ways and means of combat under the conditions of the future. Learn from the essence of the traditional tactics, gain experience from the local wars, draw upon the research results at home and abroad, and pay attention to studying the tactics adopted by our armed forces to win the superior victories so as to meet the needs of future high-tech partial war operations.

highlighting non-intelligence training

The level of tactical thinking and combat command capability are the core of non-intelligence factors, both as an important component of command and control commanding capability and as the basis for their full command of organization and command. Future high-tech war under partial warfare, the harsh battlefield environment, unpredictable circumstances, fleeting flies, commanders only have a good mental endurance, to maintain the psychological balance in the tense and complex battle command. This requires that military teaching must strengthen the cultivation of non-intellectual factors of students so that students have a good motivation for study and study hard. Through practical teaching sessions, students are trained to calmly and calmly analyze the situation and implement the battle command flexibly and decisively Ability; to approximate the actual combat confrontation exercises, so that students get an actual combat experience.

to highlight the strict teaching difficult

Strict, that is strictly in accordance with the Ordinance, regulations, decrees, teaching principles and requirements of the teaching, without lowering the standard, meticulous, serious and ensure the quality. The difficulty is to set brutal, tense, complex and difficult situations according to the requirements of actual combat. In particular, we should envisage the complex situations in which the enemy intervenes on a large scale and with a strong enemy in particular under the conditions of informationization so that the military teaching can be brought close to actual combat to the maximum Improve the adaptability of trainees to the operational environment under the conditions of partial warfare at sea of information. Strictly hard to teach, to be strict and reasonable, rare feasible, pay attention to actual results.

\section{Concluding Remarks}

Taking the practical teaching mode based on the operational process as the traction reform teaching mode can effectively focus on the actual combat level of teaching and training and the requirements of actual combat training can be run through all aspects of the training of combatant commanders to ensure that teaching and training can further focus on actual combat, The troops have moved closer together to ensure that more new command personnel capable of fighting to win victories be soon 
cultivated. However, how to solve the organic combination of teaching and military training and how to solve the "extension and supplement status" of practical curriculum not only need to carry out the research of practical teaching mode, but also need to carry out the whole process of teaching course content, The research only explores the actual combat teaching from the aspect of practical teaching.

\section{References}

[1] Sriram Venkataramanan,Atilla Dogan.A Multi-UAV Simulation for Formation Reconfiguration[R]. AIAA2004-4800. Providence,Rhode Island:AIAA Modeling and Simulation Technologies Conference and Exhibit,2003

[2] Jerome Azarewicz,Glenn Fala. Template-based Multi-agent Plan Recognition for Tactical Situation Assessment[A].In:Proceedings of 5th conference on Artificial Intelligence Applications[C],March 1989:247-254

[3] M.Valenti, T.Schouwenaars, Y.Kuwata,E.Feron and J. How Implementation of a Manned Vehicle-UAV Mission System[C].AAIA Guidance, Navigation and control Conference, Providence, RI, August 2004,AIAA2004 